
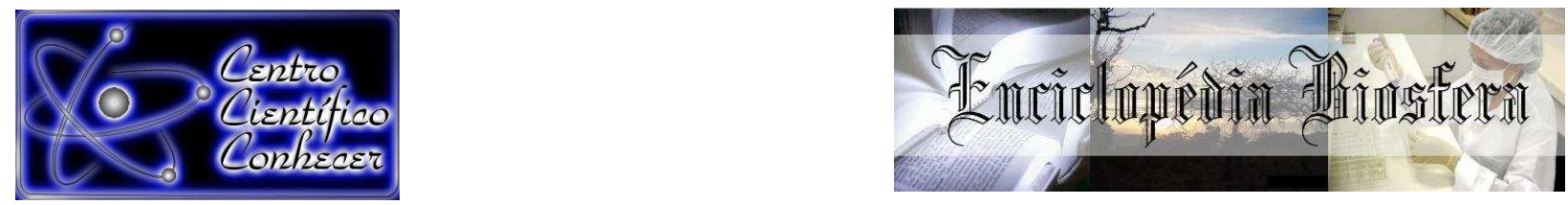

\title{
ANÁLISE TEMPORAL DA MANCHA URBANA DA REGIÃO DE LAGOA SANTA/MG A PARTIR DAS SUAS CARACTERÍSTICAS FÍSICAS
}

\section{Flávia Vieira Xavier $^{1}$, Vitor Souza Martins², André Luiz Lopes de Faria ${ }^{3}$}

1. Mestranda em Arquitetura e Urbanismo da Universidade Federal de Viçosa (flaviaxavier_88@hotmail.com) Viçosa-Brasil

2. Mestrando em Sensoriamento Remoto do Instituto Nacional de Pesquisas Espaciais, São José dos Campos-Brasil

3. Professor Doutor do Departamento de Geografia da Universidade Federal de Viçosa, Viçosa-Brasil

Recebido em: 08/09/2015 - Aprovado em: 14/11/2015 - Publicado em: 01/12/2015 DOI: http://dx.doi.org/10.18677/Enciclopedia_Biosfera_2015_060

\section{RESUMO}

A intensificação da atividade industrial no século $X X$ gerou mudanças expressivas nos espaços urbano e rural. A utilização dos recursos naturais e a capacidade do homem em alterar a paisagem elevaram o grau de urbanização em concordância com 0 crescimento da população. Diante desse cenário, 0 estudo das transformações urbanas se tornou essencial para o planejamento e na articulação de políticas públicas urbanas e regionais. O objetivo é analisar a expansão da mancha urbana de Lagoa Santa/MG utilizando as imagens do TM e OLI/Landsat para identificar as características físicas da região que influenciaram no crescimento urbano entre 1984 e 2014. As imagens orbitais do TM e OLI/Landsat permitiram a delimitação da mancha urbana na escala temporal e espacial, sendo associadas às características físicas da região como altimetria, hidrografia, declividade e infraestrutura de rodovias. A análise desses parâmetros demonstrou que houve 0 aumento da mancha urbana de $246,15 \%$ em 2014 , em relação a 1984 . O potencial para expansão urbana deve-se ao relevo suave e ondulado, alta disponibilidade hídrica e presença de rodovias (MG-010 e MG-800) interligando o município à capital mineira e impulsionando o desenvolvimento econômico da região. Assim, constatou-se que as variáveis físicas são importantes para compreender as transformações na mancha urbana e devem ser incorporadas em modelos preditivos da ocupação urbana.

PALAVRAS-CHAVE: Análise temporal, expansão urbana, planejamento urbano, sistemas de informação geográfica.

\section{TEMPORAL ANALYSIS OF URBAN AREA FOR LAGOA SANTA/MG REGION USING PHYSICAL CHARACTERISTICS.}

\begin{abstract}
The industrial intensification in 20th century has produced the significant changes in urban and rural areas. The uses of natural resources and human capacity to changing the land areas has increased sharply, which bringing a higher urbanization process in parallel to population growth. In order to understand this scenario, studies ENCICLOPÉDIA BIOSFERA, Centro Científico Conhecer - Goiânia, v.11 n.22; p.3490 2015
\end{abstract}


of the urban transformations become essential for urban planning and better proposals for urban and regional policies. The study aimed is analyze the urban expansion of Lagoa Santa/MG using TM and OLI/Landsat images and identify the influence of physical characteristics over urban growth between 1984 at 2014. The orbital images TM e OLI allowed the delimitation of urban area in temporal and spatial scales, which were associated with physical characteristics in region, such as altimetry, hydrology, slope and roads infrastructure. The analysis of parameters associated with urban growth demonstrated the increase in urban area of $246,15 \%$ in 2014 compared to 1984 . The potential of urban expansion is due to smooth slope, high hydric availability and good highway infrastructure connecting the capital of Minas Gerais and fostering the region's economic development. Thus, It was verified the physical variables are important to understand the transformation in the urban areas and should be considering into predictive models of urban occupation.

KEYWORDS: Temporal analysis, urban growth, urban planning, geographic information systems.

\section{INTRODUÇÃO}

A intensa atividade industrial a partir do século $X X$ gerou mudanças expressivas e aumentou a capacidade humana de alterar o meio em que vive, trazendo para o país um elevado grau de urbanização acompanhado de um crescimento significativo da população. Somado a isso, o processo de urbanização brasileiro apoiou-se no êxodo rural. A substituição do homem pela máquina e a estrutura fundiária concentradora levaram à migração rural-urbana de pessoas em busca de cidades que oferecessem empregos e melhores condições de vida. Como consequência disso, atualmente $84,4 \%$ da população brasileira vive no meio urbano de acordo com o Instituto Brasileiro de Geografia e Estatística - (IBGE, 2011) e a maior parte se concentra na região Sudeste.

As transformações nesses espaços tem tornado o planejamento e 0 gerenciamento das cidades um grande desafio. As relações sociais, econômicas e culturais decorrentes dessa dinamicidade apresentam inúmeros problemas derivados da forma que eles vêm sendo ocupados (AB'SABER, 1965). Para sair do caos dos grandes centros urbanos, a população tem se direcionado para cidades de pequeno e médio porte, reconfigurando o modelo de ocupação e redirecionamento as pesquisas no âmbito do planejamento urbano.

Essas cidades têm como uma de suas características o rápido crescimento de sua malha urbana, em geral pouco ordenada. Se até a década de 70 o crescimento da mancha urbana no Brasil se expandia do centro em direção à periferia, nos dias atuais o processo de urbanização se caracteriza pela ocupação dispersa, com o surgimento de pequenos núcleos isolados formados por zonas industriais, condomínios fechados, universidades, dentre outros, e se estendendo para áreas que nem sempre são adequadas a ocupação (ALVES et al., 2009).

Em regiões metropolitanas esse processo é mais intenso, ocorrendo de forma explosiva e descontrolada. A atuação dos governos municipais deve acompanhar o ritmo do crescimento urbano, entretanto, em muitos casos ele se volta para o controle da expansão, mas age também como indutor desse processo ao implantar infraestrutura e equipamentos urbanos, e ao promover o assentamento de atividades econômicas, assumindo assim o papel regulador das questões urbanas (PEIXOTO, 2005). 
Nesse contexto, o levantamento de dados do município para analisar e monitorar esses espaços serve como suporte ao planejamento e gestão territorial, aferindo a tendência de crescimento, o padrão da ocupação e as influências das características físicas e ambientais da região.

As técnicas de sensoriamento remoto, nesse sentido, consistem na utilização conjunta de sensores, equipamentos para processamento e transmissão de dados, e plataformas aéreas ou espaciais (NOVO, 1998) que permitem a obtenção de imagens e outros tipos de informações da superfície terrestre através da captação e do registro da energia refletida ou emitida pela superfície (FLORENZANO, 2002). Elas permitem, além de levantar dados de elementos do meio urbano, caracterizar a espacialização temporal das alterações ocorridas nele.

A produção de mapas como suporte para análise espacial de fenômenos está entre as principais aplicações dos Sistemas de Informação Geográfica (SIG) mostrando também ser útil para a análise de áreas urbanas. Sua aplicação permite realizar o tratamento e representação computacional de dados geográficos e recuperar informações através de sua localização espacial (CÂMARA \& MONTEIRO, 2001; CÂMARA \& QUEIROZ, 2004).

A Região Metropolitana de Belo Horizonte, composta por 34 municípios, tem registrado um acelerado crescimento urbano que se caracteriza pelo aumento da densidade de malha urbana na capital da região e, sobretudo, nas cidades do seu entorno (SOUZA \& BRITO, 2006). Lagoa Santa é um dos municípios pertencentes a essa região cuja produção do espaço não vem sendo acompanhada de um planejamento que considere suas características e aptidão física à ocupação. Ainda assim, nos últimos anos foi observado o crescimento dos índices populacionais, motivados, dentre outros fatores, por características físicas que possibilitaram a expansão da mancha urbana como relevo, hidrografia e infraestrutura.

Diante do exposto, o objetivo do estudo foi avaliar a evolução da mancha urbana de Lagoa Santa no período de 1984 a 2014 a partir da influência do relevo, hidrografia e infraestrutura utilizando imagens Landsat, técnicas de geoprocessamento e sensoriamento remoto.

\section{MATERIAL E MÉTODOS}

\section{Caracterização da área de estudo}

A área de estudo é o município de Lagoa Santa, localizado na região central do estado de Minas Gerais. Está entre os paralelos - 19,53 e - 19,73 Sul e os meridianos - 43,78 e - 43,97 Oeste (Figura 1), possui extensão territorial de $233 \mathrm{~km}^{2}$ e uma população de 52.520 habitantes (IBGE, 2011). O município está a $70 \mathrm{~km}$ do Parque Nacional da Serra do Cipó e a $35 \mathrm{~km}$ da capital mineira, Belo Horizonte. A região se caracteriza pela formação calcária na Bacia Média do Rio das Velhas. 


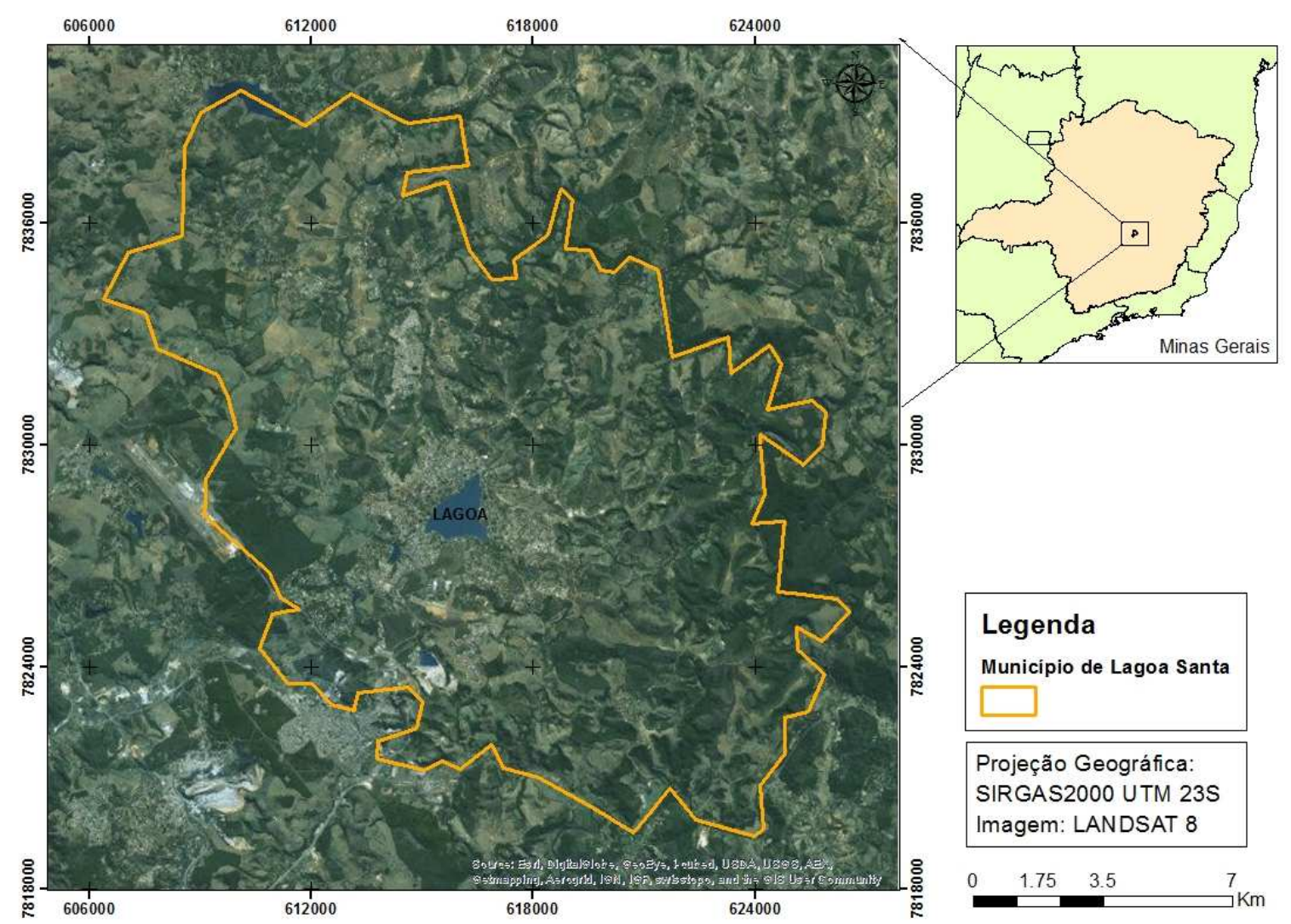

FIGURA 1: Localização do município de Lagoa Santa.

Fonte: Autores.

As características físicas da região influenciam no potencial para a expansão urbana, o que motiva o estudo do relevo (altimetria e declividade), disponibilidade hídrica e infraestrutura de rodovias. A seleção dessas variáveis usou como critério as limitações geográficas impostas pelo relevo, a disponibilidade hídrica como um recurso natural essencial para a população e a acessibilidade e atratividade a novos empreendimentos.

\section{Delimitação temporal da mancha urbana}

A base de dados orbitais utilizada na delimitação temporal da mancha urbana foram as imagens TM, ETM e OLI do programa Landsat. A escolha por diferentes sensores se deve à disponibilidade em relação ao ano, assim, as imagens adquiridas e seus respectivos anos de aquisição foram: TM/Landsat 5 em 1984, 1989 e 2010, ETM+/Landsat 7 em 2000, e OLI/Landsat 8 em 2014. O critério de seleção da qualidade das imagens foi o limiar de $15 \%$ de cobertura de nuvens e registro.

Adotou-se a delimitação da mancha urbana na série temporal de imagens através da classificação manual na escala de visualização de 1:30000, o que garantiu identificar os padrões espectrais das áreas urbanas e uma produzir limites satisfatórios para delimitação dessa classe. O processo de classificação progressivo utilizando uma composição RGB de bandas espectrais do visível visa garantir o crescimento da mancha urbana, sendo classificadas as áreas em 1984 e progressivamente adicionadas às áreas urbanas ano a ano até 2014. 
O geoprocessamento dos dados até a extração dos valores de área e perímetro consistiu na definição da projeção geográfica, composição de bandas espectrais, tratamento do brilho e contraste das imagens, individualização das manchas urbanas em cada período e edição da tabela de atributos.

\section{Caracterização física: relevo, hidrografia e infraestrutura}

A caracterização do relevo é realizada através do modelo digital de elevação ASTER GDEM (Advanced Spaceborne Thermal Emission and Reflection Radiometer), o que permite gerar uma máscara de sobreposição com as manchas urbanas e analisar a ocupação em diferentes elevações e declividades. Para a consistência do MDE com a malha hidrográfica é aplicado um procedimento para preencher as depressões espúrias (células com valor de elevação menor que das células vizinhas) e garantir a junção altimétrica com a hidrografia na geração de um modelo consistente hidrologicamente.

A utilização do MDE permite explorar a relação entre a ocupação urbana e a altimetria na região e, assim, analisar a ocorrência de novas áreas urbanas e como esse processo se desenvolveu sobre o relevo. Além da altitude, a informação gerada do MDE é a declividade.

A declividade é fator limitante para ocupação e acesso a novas áreas urbanas, sendo uma informação valiosa relacionada ao potencial de expansão da mancha urbana. A declividade é segmentada em classes de acordo com a classificação da Empresa Brasileira de Pesquisa Agropecuária - EMBRAPA (1979) e analisada sobre a mancha urbana em dois períodos: 1984 e 2014.

A disponibilidade hídrica influencia na ocupação de novas áreas por esse recurso ser essencial e limitante na implantação de novas comunidades e bairros. Existe, portanto, uma forte tendência de ocupação urbana próxima às margens de cursos d'água e o seu mapeamento permite auxiliar na análise do crescimento da mancha urbana.

Da mesma forma, a existência de rodovias que atravessam o município de Lagoa Santa é analisada como um equipamento urbano que favorece o acesso às novas áreas e interliga o município com as cidades vizinhas, o que influencia na direção de novas ocupações, como loteamentos. Assim, esse fator permitirá a compreensão da relação de dependência de infraestrutura de transportes e o desenvolvimento urbano no município de Lagoa Santa.

\section{RESULTADOS E DISCUSSÃO}

O crescimento da mancha urbana até 2014 foi de $246,15 \%$ em relação a 1984 (Figura 2). Em 1984 observou-se que a mancha principal correspondia a 75,9 $\%$ da área total e as periféricas, $24,1 \%$. Os dados demográficos de Lagoa Santa demonstraram um aumento populacional de 29.824, em 1991, para 58.702 habitantes em 2014 (população estimada pelo IBGE em 2014). Os meios para geração de emprego e oportunidades no comércio são estimulados pelas ações do estado e prefeitura municipal através de projetos de infraestrutura, incentivos fiscais de médios e pequenos empreendedores, segurança pública, locais de lazer e outros, sendo o reflexo dessa ação visto na ampliação da mancha urbana. Entretanto, aumentam o fluxo do trânsito local, a especulação do mercado imobiliário, e outros fatores que podem se tornar um problema no futuro, como consequência direta do aumento populacional. 


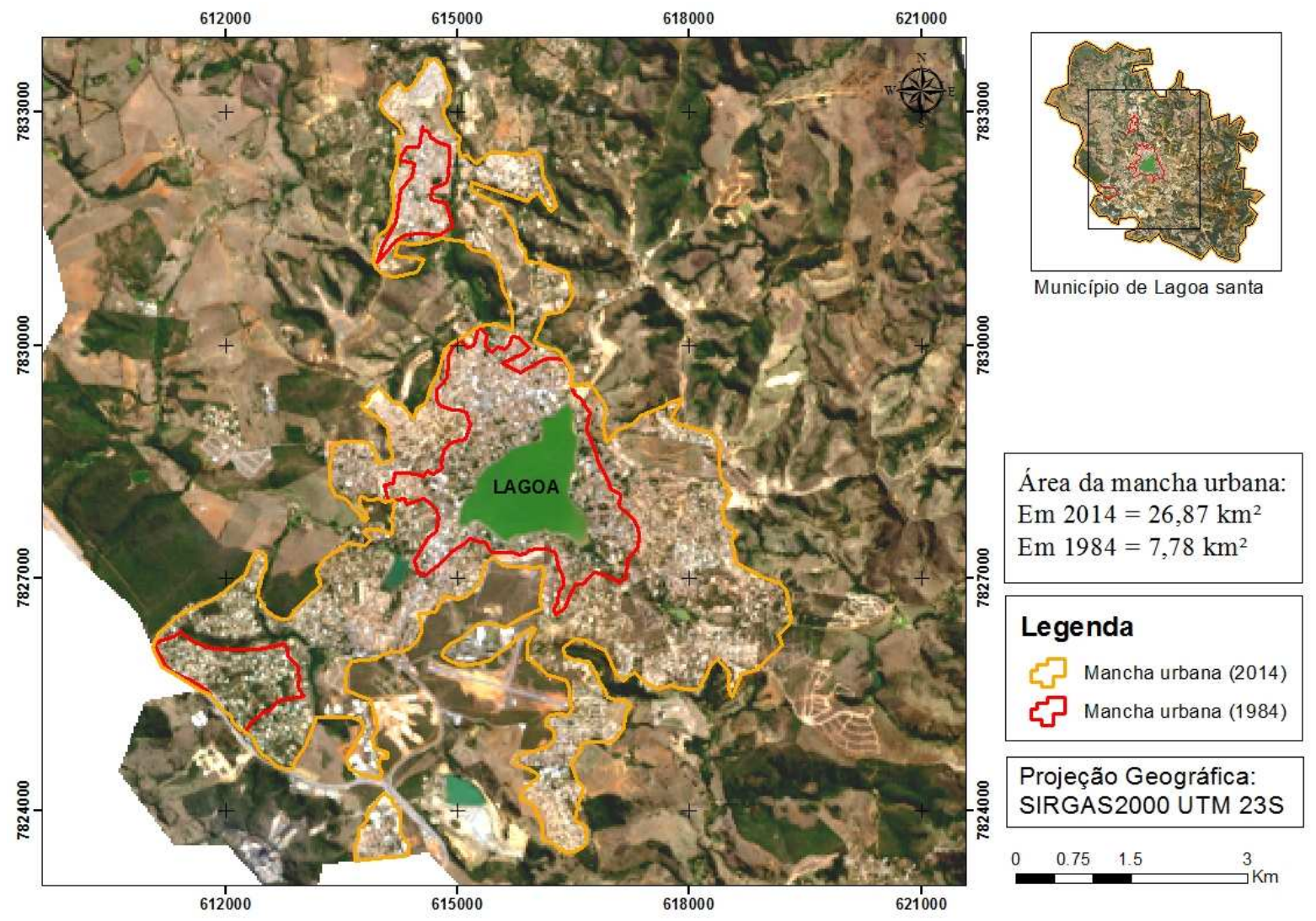

FIGURA 2: Mancha urbana nos períodos 1984 e 2014.

Fonte: Autores.

TABELA 1: Área e perímetro da mancha urbana no município Lagoa Santa.

\begin{tabular}{ccc}
\hline \multicolumn{3}{c}{ Mancha Urbana } \\
\hline Ano & Área $\left(\mathbf{k m}^{2}\right)$ & Perímetro $\mathbf{( k m})$ \\
\hline 1984 & 7,78 & 25,80 \\
1989 & 8,89 & 30,91 \\
2000 & 16,23 & 50,04 \\
2010 & 22,28 & 61,60 \\
2014 & 26,98 & 63,97 \\
\hline
\end{tabular}

Fonte: Autores.

A área da mancha urbana aumentou em 82\% entre 1989 e 2000 principalmente pela inauguração do Aeroporto Internacional de Confins. A partir desse período, houve um crescimento urbano regular com aumento de aproximadamente $10 \mathrm{~km}^{2}$ até 2014.

O processo de urbanização é influenciado pelo relevo, disponibilidade hídrica e acessibilidade, que facilitam ou dificultam a alocação de novos loteamentos e a exploração dos recursos naturais em detrimento das necessidades do homem. Diante desse fato, viu-se a importância em analisar as condições topográficas na região de Lagoa Santa e elencar os pontos favoráveis à ocupação.

O contraste da ocupação da mancha urbana em relação ao relevo entre 1984 e 2014 (Figura 3) evidencia que a ocupação se estendeu para áreas ao norte com cotas altimétricas semelhantes às do centro. No entanto, percebe-se intensa 
urbanização em parte da região leste e sul mesmo com a ocorrência de maiores altitudes.
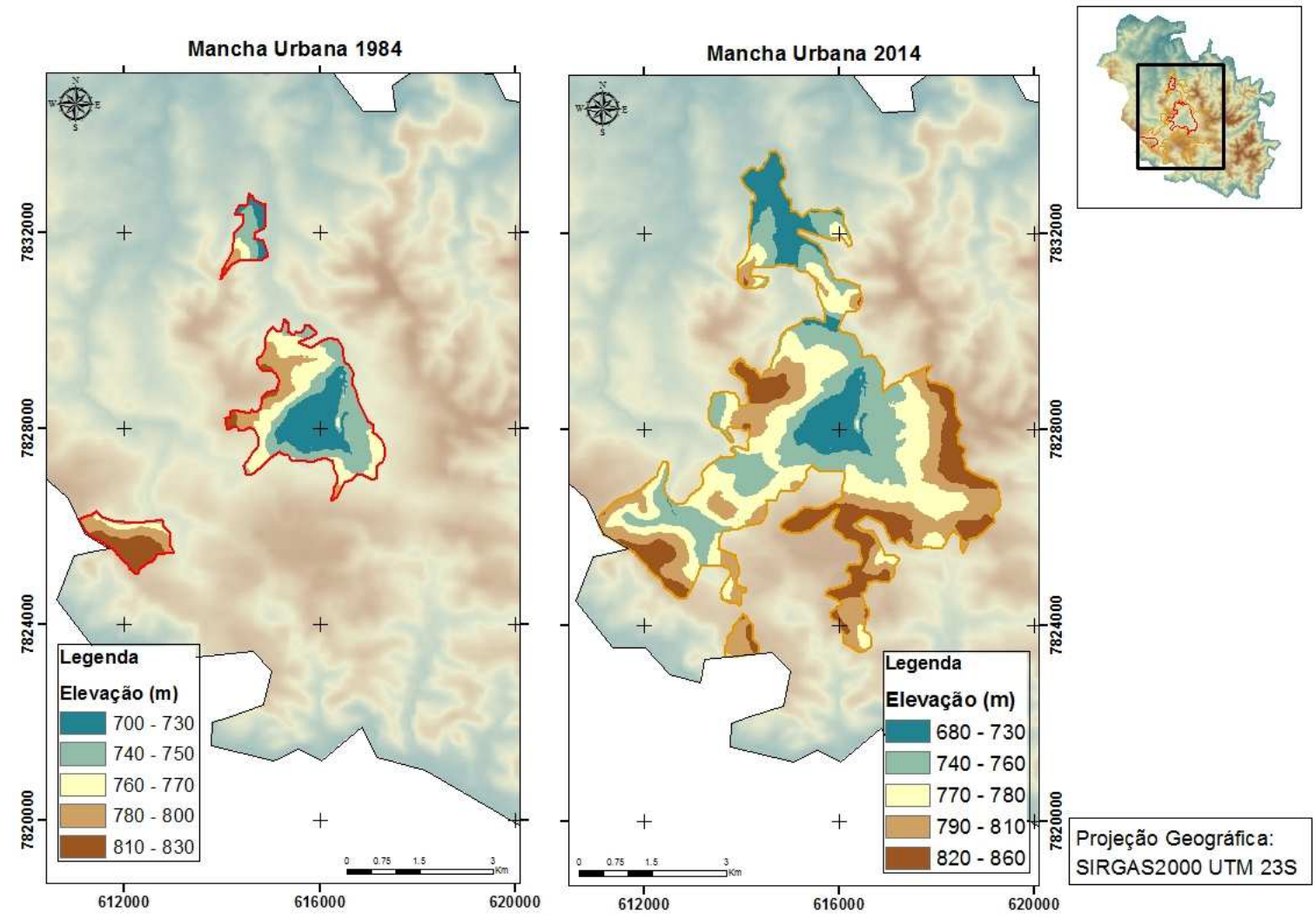

FIGURA 3: Manchas urbanas sobre altimetria do município de Lagoa Santa. Fonte: Autores.

A Figura 4 demonstra a concentração das áreas urbanas em relação às cotas altimétricas entre 1984 a 2014.

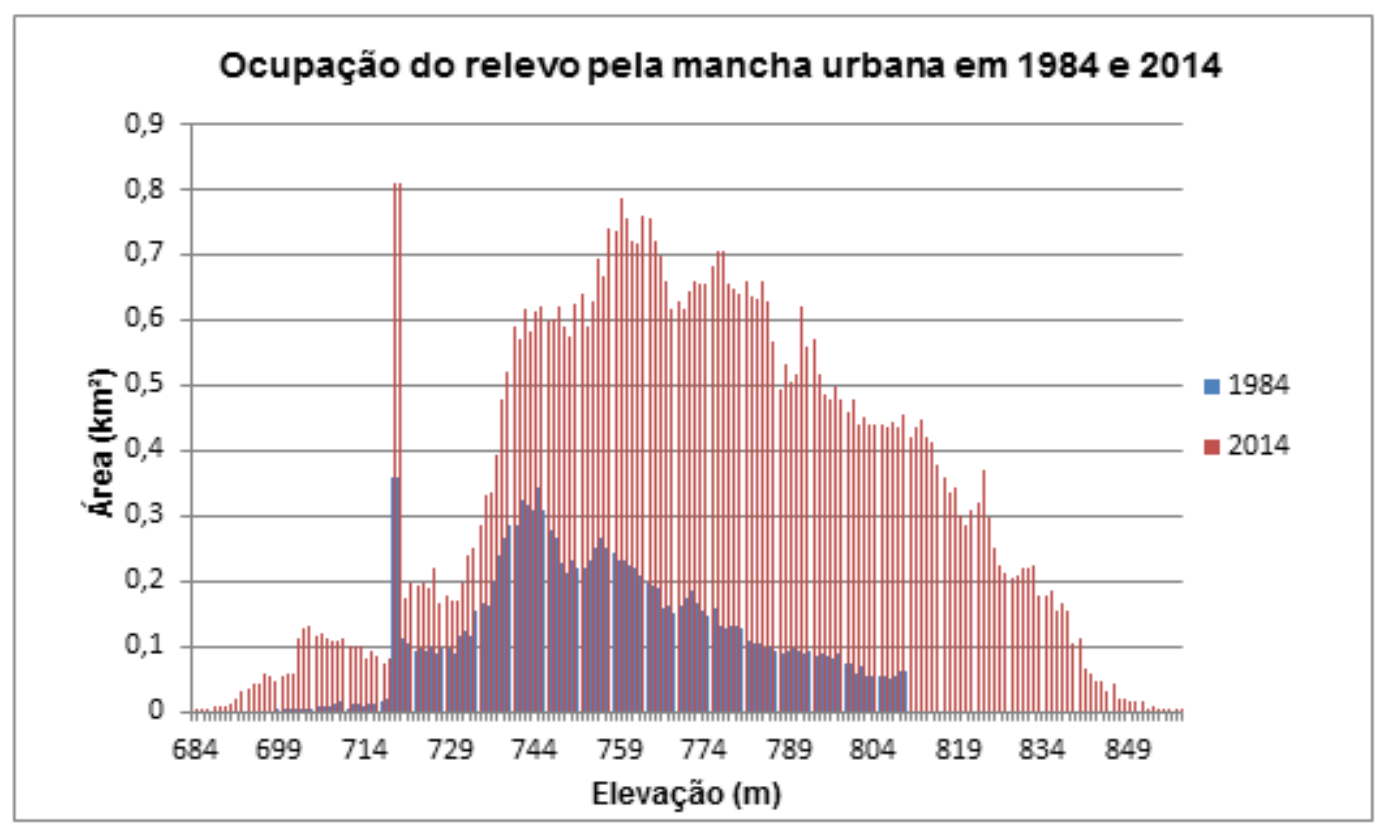

FIGURA 4: Altimetria da ocupação urbana em 1984 e 2014. Fonte: Autores. 
O relevo ocupado pela mancha urbana em 1984 possui a cota média de 755 metros, sendo o maior número de ocorrências da área urbana entre as cotas de 715 e 800 metros. A saturação de áreas planas e suaves próximas ao centro e a abertura de novos loteamentos em maiores altitudes alterou o comportamento da ocupação. A ocorrência de áreas urbanas se deslocou para a média de 777 metros e com uma área ocupada 3,5 vezes maior em 2014, sendo a cota altimétrica máxima atingida em áreas a leste do município com 859 metros.

A utilização de informações topográficas na compreensão do processo de urbanização possibilita uma análise preditiva das áreas a serem loteadas, confrontando a ocupação urbana atual com as possíveis direções de expansão e as barreiras geográficas limitantes.

A declividade, predominantemente plana a ondulada, corresponde a $77,82 \%$ da área do município, indicando uma região com relevos suaves que facilitam a ocupação e a criação de loteamentos, também por serem comumente áreas com presença de corpos hídricos.

A Figura 5 demonstra a declividade na região da mancha urbana entre $1984 \mathrm{e}$ 2014 do município de Lagoa Santa, seguindo a classificação da Embrapa (1979).

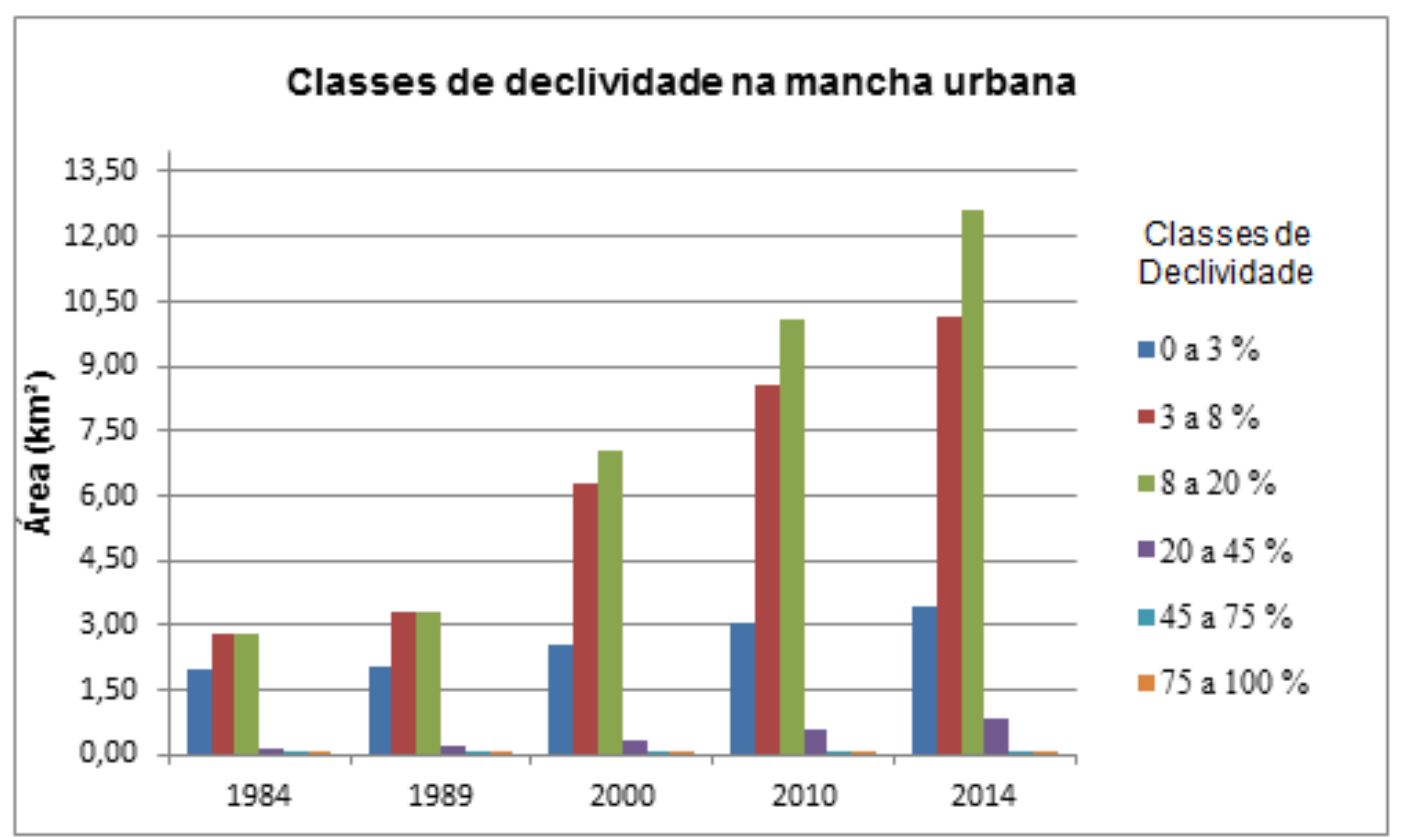

FIGURA 5: Classes de declividade no interior da mancha urbana de 1984 a 2014 em Lagoa Santa.

Fonte: Autores.

As áreas da mancha urbana em 1984 e 2014 ocupam, respectivamente, $97,91 \%$ e $96,87 \%$ do relevo em regiões planas a onduladas (declividade de 0 a 20 $\%)$, o que é esperado pela facilidade de preparação e ocupação dessas áreas menos declivosas como mencionado anteriormente.

As áreas planas não tiveram uma variação expressiva no período devido à ocupação consolidada da maioria dessas áreas até 1984, além de grande porcentagem representar a área correspondente à lagoa no centro da cidade. As áreas com declividades onduladas ( 3 a $20 \%$ ) foram as mais ocupadas, revelando o potencial e os benefícios de se lotear e construir em áreas com relevo suave. As 
altas declividades, 45 a $100 \%$, não apresentaram expressivo nível de ocupação, comprovando que a facilidade de acesso e construção são fatores importantes para que a expansão urbana ocorra.

Quanto à capacidade hídrica, Lagoa Santa conta com mais de 25 córregos. Através da utilização do mapeamento hidrográfico do IBGE existem $447 \mathrm{~km}$ de cursos d'água no município, com uma densidade de drenagem igual a 2,05 km/km².

Historicamente, a ocupação no município ocorreu próxima às margens da Lagoa Central e, posteriormente, se expandiu para novas áreas, também próximas de recursos hídricos, demonstrando a necessidade de se viver em regiões conforme a disponibilidade hídrica. Hoje, a mancha urbana inclui 32,24 km de cursos d'água dos $447 \mathrm{~km}$ cursos d'água existentes no limite do município. O contraste do número de nascentes entre 1984 e 2014 é grande, aumentando de quatro para 22 nascentes dentro da mancha urbana. A análise espacial permite visualizar a distribuição das nascentes e a geometria da distribuição da área urbana entre os dois períodos (Figura 6).

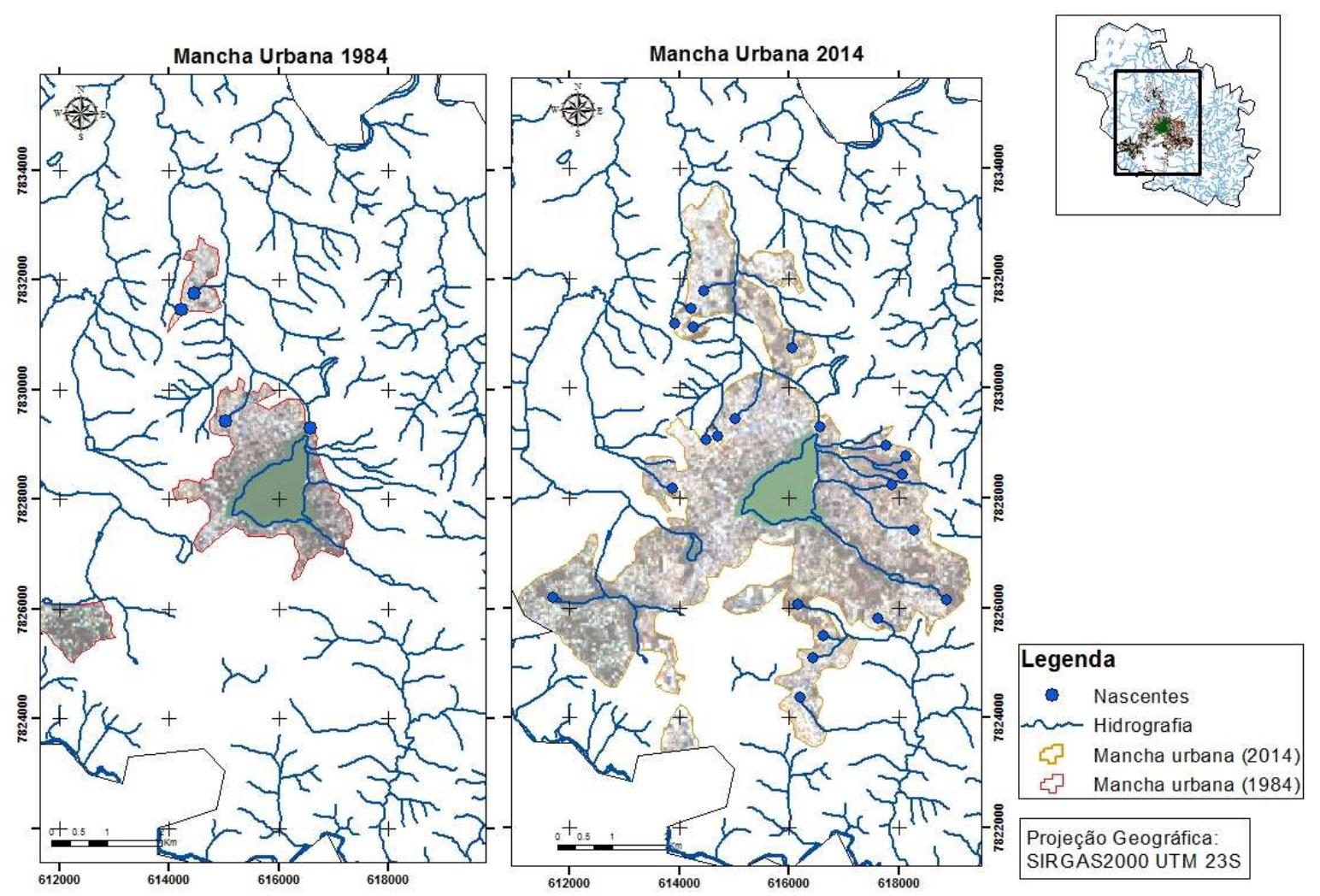

FIGURA 6: Mancha urbana sobre a hidrografia em 1984 e 2014. Fonte: Autores.

A mancha urbana expandiu na direção norte, sudoeste e sul com uma tendência paralela aos cursos d'água e englobando cabeceiras de rios. A alta ocorrência das ocupações urbanas em áreas planas e a localização dos corpos hídricos nas partes baixas do relevo abrem espaço para discussões ambientais se relacionarmos a disponibilidade hídrica com a condição topográfica.

Como pode ser visto na Figura 7, a infraestrutura e a presença de rodovias também influenciaram no sentido da expansão urbana, com destaque para a MG- 
010 e MG-800 que interligam o município de Lagoa Santa com a capital mineira, a Cidade Administrativa de Minas Gerais, o Aeroporto Internacional de Confins e com o Parque Nacional da Serra do Cipó.

A reforma da MG-010 com a implantação da Linha Verde interligando Belo Horizonte ao Aeroporto Internacional de Confins possibilitou o maior e melhor fluxo de veículos até Lagoa Santa. A ocupação da população nas margens da rodovia na mancha urbana principal marca a importância do acesso para o desenvolvimento do centro municipal. A sobreposição da mancha urbana em 2014 com as rodovias MG010 e 800 demonstram que o seu crescimento se deu acompanhando as margens da rodovia, até mesmo em regiões periféricas como nas margens da MG-800, em um trecho de $1,8 \mathrm{~km}$.

Os dois agrupamentos urbanos que antes eram dispersos se uniram à mancha urbana principal pela influência da MG-800, representando um trecho de aproximadamente $3,8 \mathrm{~km}$, e $8,2 \mathrm{~km}$ da MG-010.A operação de voos nacionais e internacionais no aeroporto localizado a $13 \mathrm{~km}$ do município também influenciou no aumento de investimentos na região. Ainda, a região é conhecida pela concentração de indústrias cimenteiras, metalúrgicas e de extração de calcário (Figura 7).
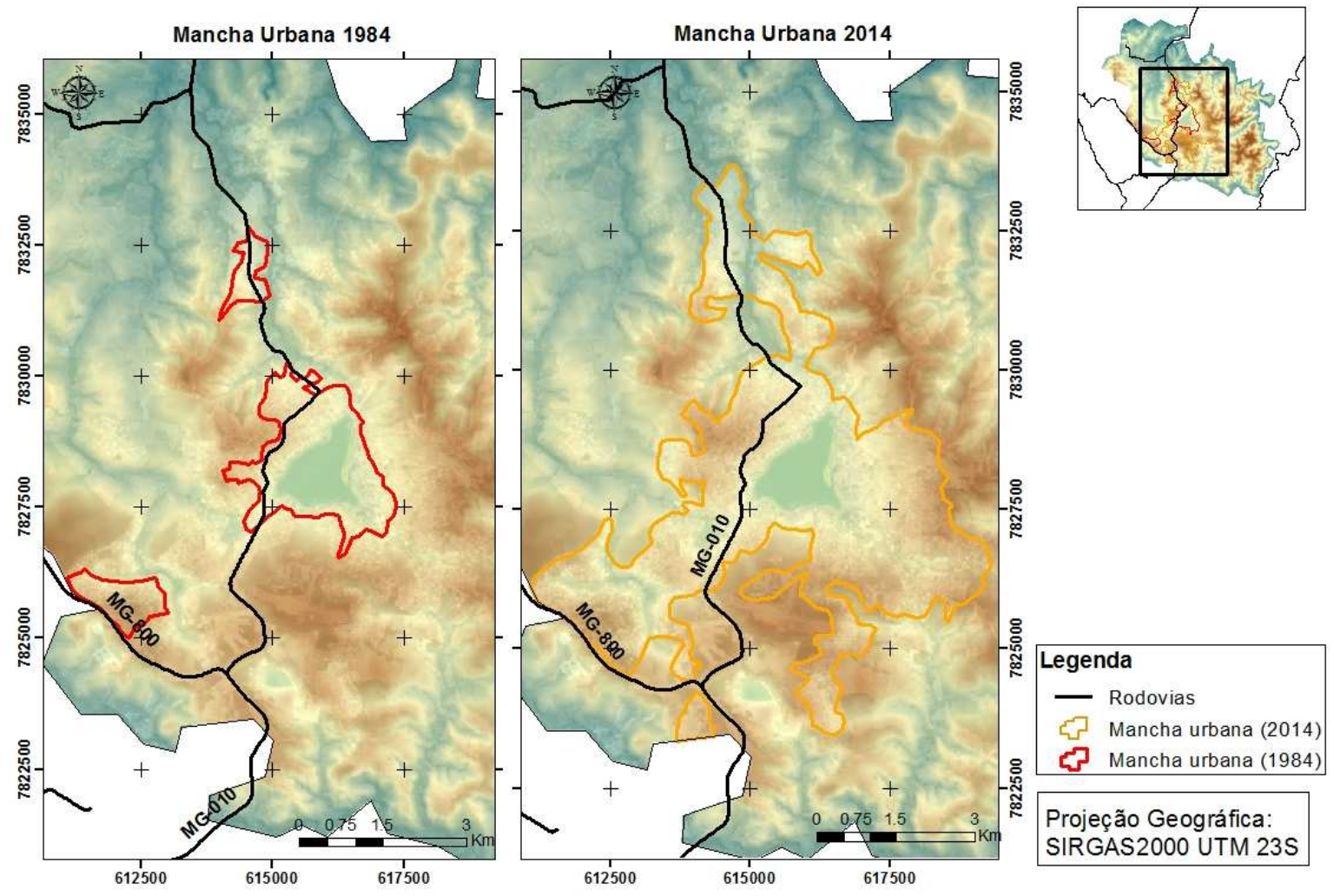

FIGURA 7: Mancha urbana sobre as rodovias MG-010 e MG-800 em 1984 e 2014. Fonte: Autores.

Dessa forma, a localização estratégica de Lagoa Santa tornou os investimentos mais viáveis e trouxe investidores do setor imobiliário, da indústria e do comércio para transformar a cidade em uma região atrativa principalmente aos moradores da capital mineira que buscam condições de vida interioranas. Ressaltase que outros fatores como os de ordem política, econômica e social são importantes para compreender a expansão urbana e o aumento da população no 
município, no entanto, esse estudo se restringe a análise do crescimento da mancha urbana considerando o potencial das características físicas para a expansão. Ficou evidente que o sentido da expansão é dependente das condições de acesso, relevo e hidrografia, sendo variáveis importantes de incorporar em modelos preditivos da ocupação urbana. A disponibilidade e uso de imagens de satélite amplia a visão do planejamento urbano no espaço e no tempo, sendo uma ferramenta com potencial para a gestão pública.

\section{CONCLUSÃO}

A mancha urbana em Lagoa Santa no ano de 2014 cresceu 246,15 \% em relação a 1984. Essa acentuada expansão é influenciada pelo relevo suave e ondulado, a alta disponibilidade hídrica, a passagem das rodovias MG-010 e MG800 pelo município, ao aumento da população e demais fatores não mencionados nesse estudo.

A concentração das áreas urbanas em relação às cotas altimétricas e à declividade mostrou que a mancha urbana se estendeu para áreas com baixas cotas e suaves declividades, mas que em função da saturação de áreas planas e onduladas próximas à região central, ocorreu uma alteração no comportamento da ocupação, que em 2014 já apresentava intensa urbanização em áreas de maior altitude e declividade.

Quanto à disponibilidade hídrica, a existência da Lagoa Central foi primordial para dar início às ocupações em Lagoa Santa, que posteriormente se estenderam ao longo dos $32,24 \mathrm{~km}$ de cursos d'água comprovando a dependência da existência desse recurso para a permanência da população no local.

Por fim, a passagem das rodovias MG-010 e MG-800 dentro do município e a criação da Linha Verde facilitaram o acesso à Lagoa Santa. Além disso, sua localização estratégica na Região Metropolitana de Belo Horizonte, do Aeroporto Internacional de Confins, da Cidade Administrativa de Minas Gerais e do Parque Nacional da Serra do Cipó fizeram crescer o interesse e investimentos na cidade, atraindo grande contingente populacional.

Assim, os resultados gerados nas análises temporais através de dados de sensoriamento remoto e sistemas de informação geográfica permitiram uma abordagem que muito contribui para o desenvolvimento de novos projetos urbanos e fornece subsídios à gestão e planejamento das dinâmicas urbano-regionais. Os indicativos dos novos vetores de expansão urbana auxiliam na tomada de decisões futuras como controle da ocupação em áreas de relevo acidentado, ribeirinhas ou próximas a nascentes.

\section{REFERÊNCIAS}

AB'SABER, A. N. O sítio urbano de Porto Alegre: estudo geográfico. Boletim Paulista de Geografia, São Paulo, n. 42, p. 3-30, 1965.

ALVES, C. D.; PEREIRA, M. N.; FLORENZANO, T. G.; SOUZA, I. M. Análise orientada a objeto no mapeamento de áreas urbanas com imagens Landsat. Boletim de Ciências Geodésicas, Curitiba, v. 15, n. 1, p. 120-141, Jan/Mar , 2009.

CÂMARA, G.; MONTEIRO, A. M. V. Conceitos básicos em Ciência da Geoinformação. In: CÂMARA, G.; DAVIS, C.; MONTEIRO, A. M. V. Introdução à Ciência da Geoinformação. São José dos Campos: INPE, 2001. 
CÂMARA, G.; QUEIROZ, G. R. Arquitetura de sistemas de informação geográfica. In: CÂMARA, G., MONTEIRO, A. M.; MEDEIROS, J. S. (editores). Introdução à Ciência da Geoinformação. São José dos Campos: INPE, 2004.

EMBRAPA. Empresa Brasileira de Pesquisa Agropecuária. Serviço Nacional de Levantamento e Conservação de Solos. Reunião Técnica de Levantamento de Solos. Rio de Janeiro, 1979. 83 p.

FLORENZANO, T. G. Imagens de Satélite para Estudos Ambientais. São Paulo: Oficina de Textos, v. 1, 2002. $104 \mathrm{p}$.

IBGE. Censo Demográfico 2010. Características da população e dos Domicílios. Resultados do Universo. 2011. Rio de Janeiro: IBGE, 2011. 270 p. Disponível em: $<$ http://biblioteca.ibge.gov.br/visualizacao/periodicos/93/cd_2010_caracteristicas_pop upopul_domicilios.pdf.> Acesso em: Setembro 2014.

IBGE. Cidades@. Instituto Brasileiro de Geografia e Estatística, 2014. Disponivel em: <http://cidades.ibge.gov.br/xtras/perfil.php?codmun=313760>. Acesso em: Setembro 2014.

NOVO, E. M. L. M. Sensoriamento Remoto: Princípios e Aplicações. 2ª ed. São Paulo: Edgard Blucher, 1998. 388 p.

PEIXOTO, M. C. D. Expansão urbana e proteção ambiental: um estudo a partir do caso de Nova Lima/MG. In: XI Encontro Nacional de Pós-Graduação e Pesquisa em Planejamento Urbano e Regional, 11, 2005. Salvador. Anais... Salvador: ANPUR, 2005.2 Disponível em: <http://unuhospedagem.com.br/revista/rbeur/index.php/anais/article/view/2733/2673 > Acesso em: Agosto 2014.

SOUZA, R. G. V.; BRITO, F. R. A. A expansão urbana da Região Metropolitana de Belo Horizonte e suas implicações para a redistribuição espacial da população: a migração dos ricos. In: Encontro de Estudos Populacionais, 15, 2006. Caxambu. Resumos... Caxambu: ABEP, 2006. 21 p. Disponível em: <http://www.abep.nepo.unicamp.br/encontro2006/docspdf/ABEP2006_408.pdf> Acesso em: Setembro 2014. 